\title{
Inhibitors of PARP-1 exert inhibitory effects on the biological characteristics of hepatocellular carcinoma cells in vitro
}

\author{
XIAORONG MAO ${ }^{1 *}$, SENRONG DU ${ }^{2 *}$, ZHONGXIA YANG ${ }^{1}$, \\ LITING ZHANG $^{1}$, XUEBIN PENG ${ }^{1}$, NI JIANG ${ }^{1}$ and HAIYU ZHOU ${ }^{3}$ \\ ${ }^{1}$ Department of Infectious Disease, The First Hospital of Lanzhou University, Lanzhou, \\ Gansu 730000; ${ }^{2}$ Department of Infectious Disease, Lanzhou Pulmonary Hospital, Lanzhou, Gansu 730046; \\ ${ }^{3}$ Department of Orthopedics, The Second Hospital of Lanzhou University, Lanzhou, Gansu 730030, P.R. China
}

Received February 28, 2016; Accepted February 9, 2017

DOI: $10.3892 / \mathrm{mmr} .2017 .6568$

\begin{abstract}
It has been confirmed that the inhibitors of poly ADP-ribose polymerF(^9ase-1 (PARP-1) can inhibit the proliferation, apoptosis and invasion of tumor cells. However, the effects of inhibitors of PARP-1 on hepatocellular carcinoma remain to be elucidated. The aim of the present study was to investigate the effect of three types of PARP-1 inhibitor on the proliferation, apoptosis and migration of hepatocellular carcinoma in vitro. An MTT assay was performed to detect the proliferation of HepG2 cells following treatment with the PARP-1 inhibitors, AG014699, BSI-201 and AZD-2281. Flow cytometry was used to detect the apoptosis of HepG2 cells, Western blot analysis was used to detect the protein expression of Casepase-3, Casepase-8, B-cell lymphoma 2 (Bcl-2)-associated X protein (Bax), Bcl-2, phosphatase and tensin homolog (PTEN), tissue inhibitor of metalloproteinase (TIMP) 3 and matrix metalloprotease (MMP) 3. A Transwell assay was performed to detect the migration of HepG2 cells. The results showed that AG014699, BSI-201 and AZD-2281 had an inhibitory effect on the proliferation of HepG2 cells in a time- and concentration-dependent manner. AG014699 at concentrations of 10,30 and $50 \mu \mathrm{mol} / 1$, and BSI-201 at concentrations of 20, 40 and $60 \mu \mathrm{mol} / 1$ induced the apoptosis of HepG2 cells, and the apoptotic rates were particularly high at $48 \mathrm{~h}(31$, vs. $0.01 \% ; \mathrm{P}<0.01$ and 24.12 , vs. $0.03 \%$, respectively; $\mathrm{P}<0.01$ ). The protein expression levels of Caspase 3, Caspase 8, Bax, PTEN and TIMP 3 increased with increasing drug concentrations, whereas the protein levels of Bcl-2 and MMP3 decreased with increasing drug concentrations, and were
\end{abstract}

Correspondence to: Professor Haiyu Zhou, Department of Orthopedics, The Second Hospital of Lanzhou University, 82 Cuiyingmen, Chengguan, Lanzhou, Gansu 730030, P.R. China E-mail: mxr2013@126.com

*Contributed equally

Key words: poly ADP-ribose polymerase-1, inhibitor, hepatocellular carcinoma cell, proliferation, apoptosis, migration significantly different compared with those in the control group $(\mathrm{P}<0.01)$. In conclusion, AG014699, BSI-201 and AZD-2281 inhibitors of PARP-1 significantly inhibited the proliferation of HepG2 cells, however, AG014699 and BSI-201 demonstrated more sensitivity, induced apoptosis and inhibited migration of the hepatocellular carcinoma cells, which may be associated with alterations of the apoptosis signaling pathway and the expression of proteins associated with migration.

\section{Introduction}

The incidence and mortality rates of primary liver cancer are the fifth and second highest of all types of cancer in the world, respectively, and hepatocellular carcinoma has a poor prognosis with a 5 -year survival rate of $<5 \%$ (1). Current therapeutic methods are unable to effectively improve the prognosis of patients with hepatocellular carcinoma. Therefore, novel therapeutic strategies are urgently required. The poly ADP-ribose polymerase (PARP) family is involved in the regulation of several cellular functions, including DNA damage and repair, RNA transcription, cell signaling, cell cycle regulation and mitosis. It has been confirmed that PARP, being involved in DNA damage and repair, is closely associated with tumor therapies (2).

The PARP family includes PARP-1, PARP-2, PARP-3, Vault-PARP tankyrase (TANK-1, TANK-2 and TANK-3) and other subtypes. Several studies $(3,4)$ have focused on the role of PARP-1 in cancer, diabetes and inflammation. PARP-1 is expressed at high levels in tumor cells with BRCA1/2 mutations, and PARP-1 inhibitors can be used as agents for the treatment of tumor cells with breast cancer (BRCA)1/2 deficiency, including breast cancer and ovarian cancer cells. PARP-1 inhibitors have been used in clinical phase I and II trials for treating BRCA-1/2 (-) breast cancer and ovarian cancer $(3,4)$. In addition, basic investigations have found that the PARP-1 inhibitor, olaparib, can increase the inhibition of radiation in Ewing's sarcoma cell proliferation and induce the apoptosis of sarcoma cells (5). Other studies have shown that PARP-1 inhibitors can affect the proliferation, apoptosis and invasion of tumor cells (6), and enhance the effects of chemotherapy on tumor cells (3), particularly in breast and ovarian cancer with BRCA1/2 mutations (7). However the effect of 
PARP-1 inhibitors on liver cancer cells remains to be fully elucidated (8).

It has been confirmed that phosphatase and tensin homolog (PTEN) is a tumor suppressor gene involved in the phosphoinositide 3-kinase/AKT/mammalian target of rapamycin signaling pathways to maintain normal physiological activity of cells, negatively regulates tumor cell cycle, induces tumor cell apoptosis, and inhibits tumor cell invasion and metastasis (9). Additionally, matrix metalloproteinases (MMPs) are important in tumor invasion and migration. The abnormal metabolism of extracellular matrix can lead to tumor metastasis when the homeostasis between MMP and tissue inhibitor of metalloproteinase (TIMP) is interrupted. MMP 3 is an important member of the MMP family, and is capable of degrading extracellular matrix involved in tissue morphogenesis, physiological and pathological processes, and tumorigenesis (10). In the present study, three types of PARP-1 inhibitor were used, AG014699, BSI-201a and AZD-2281, which have been used in previous clinical trials for the treatment of breast cancer (11). These were used to observe the effect of PARP-1 inhibitors on the expression of PTEN, MMP and TIMP, examine their effects on the proliferation, apoptosis and migration of human hepatoma HepG2 cells in vitro, and examine the possible underlying mechanisms.

\section{Materials and methods}

Materials. The HepG2 cells were provided by the Institute of Modern Physics, Chinese Academy of Science (Lanzhou, China). DMEM was purchased from Hyclone; GE Healthcare Life Sciences (Logan, UT, USA); fetal bovine serum (FBS) was purchased from Sijiqing Company (Hangzhou, China). MTT was purchased from Amresco, LLC (Solon, OH, USA), BSI-201 was purchased from Sigma; Merck KGaA (Darmstadt, Germany). AZD2281 and AG014699 were purchased from Selleck Chemicals (Shanghai, China). The primary antibodies (GAPDH, Caspase 3, Caspase 8, Bcl-2, Bax, PTEN, TIMP 3 and MMP3) were purchased from Affinity Biologicals Inc. (Ancaster, ON, Canada). The secondary antibody was purchased from Beyotime Institute of Biotechnology (Haimen, China).

Cell culture. The HepG2 cells were cultured in DMEM medium containing $10 \% \mathrm{FBS}$, and $100 \mathrm{U} / \mathrm{ml}$ antibiotics (penicillin:streptomycin, 1:1) was added. The cells were incubated at $37^{\circ} \mathrm{C}$ in an incubator with $5 \% \mathrm{CO}_{2}$ and $95-98 \%$ relative humidity. Cells at the logarithmic phase were treated with $0.25 \%$ trypsin and passaged.

MTT assay. The HepG2 cells were cultured at a density of $5 \times 10^{3} / \mathrm{ml}$ in 96 -well plates, and divided into the following control and drug groups: Blank group (complete medium); control group (complete medium containing <1\% DMSO); AG014699 group (5, 10, 20, 40 and $80 \mu \mathrm{mol} / \mathrm{l})$; AZD2281 group (50, 100, 200, 400 and $800 \mu \mathrm{mol} / \mathrm{l})$; BSI-201 group (10, 20, 40, 60 and $80 \mu \mathrm{mol} / \mathrm{l})$. Each group included six wells. Subsequently, $20 \mu \mathrm{l}$ MTT was added to each well following 24, 48, 72 and $96 \mathrm{~h}$ of culture. After $4 \mathrm{~h}$, the culture medium was aspirated and $150 \mu 1$ DMSO was added to each well. The optical density (OD) was measured on an absorbance microplate reader with a wavelength of $570 \mathrm{~nm}$. The inhibition rate was calculated according to the following formula: Inhibition ratio $=1-\left(\mathrm{OD}_{\mathrm{drug}}\right.$ group $\left.-\mathrm{OD}_{\text {control group }}\right) /\left(\mathrm{OD}_{\text {control group }}-\mathrm{OD}_{\text {blank group }}\right) \times 100 \%$.

Flow cytometric analysis. The HepG2 cells at the logarithmic phase were seeded into 6 -well plates at a density of $2.5 \times 10^{4} / \mathrm{ml}$. The PARP-1 inhibitors AG014699 and BSI-201, which were sensitive to the HepG2 cells, were selected for the apoptotic assay. After 48 h, the cells were cultured with AG014699 at concentrations of 10,30 and $50 \mu \mathrm{mol} / 1$, or BSI-201 at concentrations of 20,40 and $60 \mu \mathrm{mol} / 1$ for $48 \mathrm{~h}$ at $37^{\circ} \mathrm{C}$, following which the cells were digested with $0.25 \%$ trypsin and washed twice with PBS. To $100 \mu \mathrm{l}$ of the solution $\left(1 \times 10^{4}\right.$ cells), $5 \mu \mathrm{l}$ of annexin V-fluorescein isothiocyanate (BD $\mathrm{GmbH}$, Heidelberg, Germany) and $10 \mu \mathrm{l}$ propidium iodide $(20 \mathrm{mg} / \mathrm{ml}$; Sigma-Aldrich; Merck KGaA, Darmstadt, Germany) were added. Analysis was performed using a FACScan and CELLQuest software version 2.1.4.7 (BD Biosciences, Franklin Lakes, NJ, USA).

Western blot analysis. The HepG2 cells at the logarithmic phase were seeded into 6 -well plates at a density of $5 \times 10^{4} / \mathrm{ml}$. After 48 h, AG014699 (10, 30 and $50 \mu \mathrm{mol} / \mathrm{l})$ or BSI-201 (20, 40 and $60 \mu \mathrm{mol} / \mathrm{l})$ were added then cultured for $48 \mathrm{~h}$ at $37^{\circ} \mathrm{C}$. Cells were digested with $0.25 \%$ trypsin containing $0.02 \%$ EDTA. After $1 \mathrm{~min}$, the cells were gently agitated with $1.5 \mathrm{ml}$ of PBS buffer. After centrifugation at $55 \mathrm{x}$ g at $4^{\circ} \mathrm{C}$ for $5 \mathrm{~min}$, the supernatant was removed and washed three times with PBS. Then $200 \mu$ l of PMSF and RIPA lysate (1:100) added for $30 \mathrm{~min}$. The lysate was slowly agitated with a $2 \mathrm{ml}$ syringe and allowed to lyse sufficiently. The centrifuge was preheated to $4^{\circ} \mathrm{C}$ and the lysate centrifuged at 8,051 $\mathrm{x} g$ for 15 min. The supernatant was dispensed into a $100 \mu \mathrm{l}$ centrifuge tube and the protein concentration was measured using a Pierce BCA Protein Quantitative Assay kit (Pierce; Thermo Fisher Scientific, Inc., Waltham, MA, USA). Sample proteins were separated by electrophoresis on a $12 \%$ SDS-PAGE gel and transferred onto polyvinylidene difluoride. Membranes were blocked with $5 \%$ non-fat milk powder in TBST buffer (Tris-buffered saline, $0.05 \%$ Tween 20) and incubated at $4^{\circ} \mathrm{C}$ for $2 \mathrm{~h}$ with primary antibodies against Caspase 3 (AF835; 1:1,000), Caspase 8 (AF705; 1:1,000), Bax (AF820; 1:1,000), Bcl-2 (AF810; 1:1,000), PTEN (AF847; 1:1,000), TIMP3 (AF0265; 1:1,000) and MMP3 (AF548; 1:1,000; all from Affinity Biologicals Inc.). The membranes were washed three times in TBST and then incubated for $2 \mathrm{~h}$ at room temperature with the secondary antibody (horseradish peroxidase-labeled goat anti-rabbit; s0001; 1:1,000; Beyotime Institute of Biotechnology, Haimen, China) and then washed three times in TBST. The gray value of each band was analyzed using ImageJ software, version 2.1.4.7 (National Institutes of Health, Bethesda, MD, USA).

Cell migration analysis. The HepG2 cells at the logarithmic growth phase were starved for $12 \mathrm{~h}$, and then digested using trypsin. The cells, in DMEM containing 5\% FBS, were seeded into a Transwell chamber at a density of $5 \times 10^{5}$ cells $/ \mathrm{ml}$. The chamber was placed into 24-well plates, and placed in an incubator at $37^{\circ} \mathrm{C}, 5 \% \mathrm{CO}_{2}$ overnight. Following incubation, the medium in the chamber was removed, and AG014699 
A

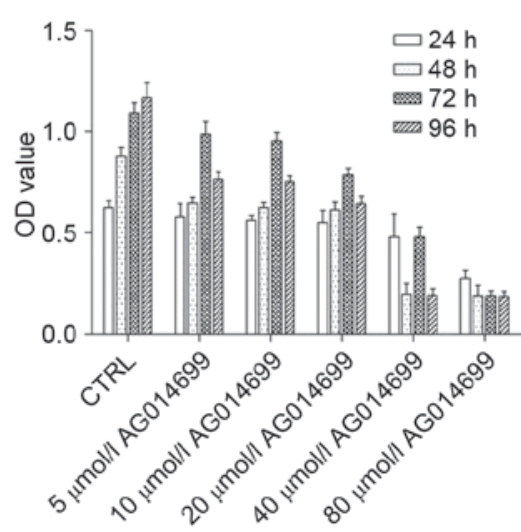

B

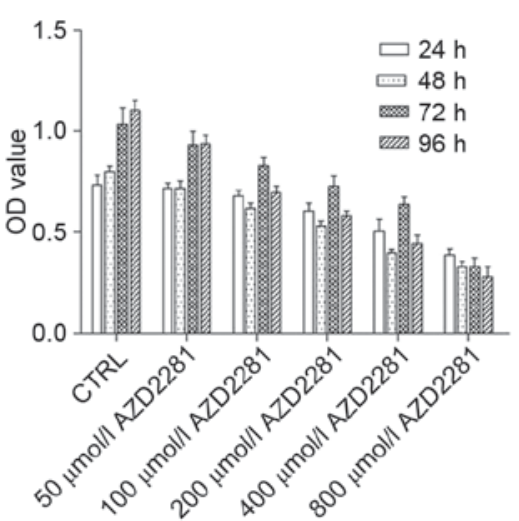

C

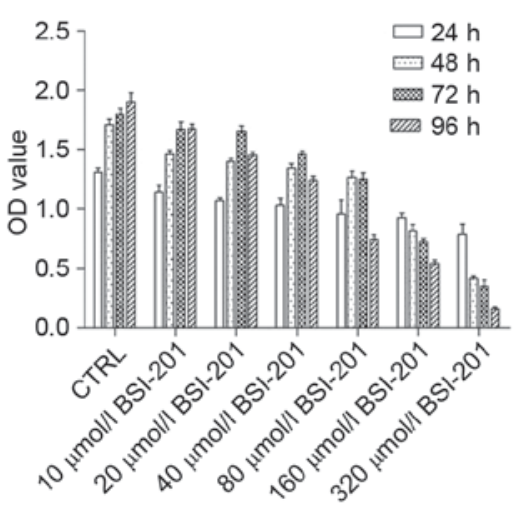

Figure 1. Effects of the poly ADP-ribose polymerase-1 inhibitors (A) AG014699, (B) AZD2281 and (C) BSI-20 on the proliferation of HepG2 cells. CTRL, control; OD, optical density.

or BSI-201 were added with final concentrations of 5 and $10 \mu \mathrm{mol} / 1$, respectively. The control group contained $300 \mu \mathrm{l}$ serum-free medium with $<1 \%$ DMSO. The lower chamber contained $600 \mu \mathrm{l}$ DMEM containing $25 \%$ FBS. The cells were placed into the cell incubator and cultured for $48 \mathrm{~h}$ at $37^{\circ} \mathrm{C}$. The medium was then removed and the cells were washed twice in PBS buffer, followed by fixing in $4 \%$ formaldehyde for 3-5 min at room temperature and treatment with methanol for $20 \mathrm{~min}$. Subsequently, the cells were washed twice with PBS, and the dry Transwell chamber was placed into the lower chamber for staining with crystal violet for $15 \mathrm{~min}$. The cells were washed twice in PBS and visualized using an inverted microscope to examine cell migration.

Statistical analysis. The results are expressed as the mean \pm standard deviation. SPSS 17.0 statistical software (SPSS, Inc., Chicago, IL, USA) was used to analyze data. An independent t-test was used to determine the differences between two groups. One-way analysis of variance was used to analyze the differences between multiple groups. $\mathrm{P}<0.05$ was considered to indicate a statistically significant difference.

\section{Results}

Different concentrations of AG014699, BSI-201 and AZD2281 exert different inhibitory effects on the proliferation of HepG2 cells. The results showed that different concentrations of the PARP-1 inhibitors inhibited the proliferation of HepG2 cells. As concentrations increased, the inhibitory effect was enhanced (Fig. 1). After $24 \mathrm{~h}$, the half maximal inhibitory concentrations of AG014699, BSI-201 and AZD2281 were 80, 160 and $800 \mu \mathrm{mol} / \mathrm{l}$, respectively. After $48 \mathrm{~h}$, the half maximal inhibitory concentrations of AG014699, BSI-201, AZD2281 were 20, 30 and $400 \mu \mathrm{mol} / \mathrm{l}$, and at $96 \mathrm{~h}$, the half maximal inhibitory concentrations were 10,25 and $300 \mu \mathrm{mol} / 1$ at $72 \mathrm{~h}$, and 5, 20 and $200 \mu \mathrm{mol} / 1$.

AG014699 and BSI-201 induce the apoptosis of HepG2 cells. According to the results of the MTT assay, the two PARP-1 inhibitors, AG014699 and BSI-201, were selected as they exhibited sensitive inhibitory effects on the HepG2 cells. The results showed that the apoptotic rates of the HepG2 cells increased with increasing concentrations of these two inhibitors. There were significant differences between the groups ( $\mathrm{P}<0.01$; Fig. 2). Similarly, in the HepG2 cells treated with 20, 40 or $60 \mu \mathrm{mol} / 1 \mathrm{BSI}-201$ for $48 \mathrm{~h}$, the apoptotic rates of the HepG2 cells also increased, and significant differences were found between the groups $(\mathrm{P}<0.01 ;$ Fig. 3).

Expression levels of apoptosis-associated proteins are induced by AG014699 and BSI-201. Following treatment of cells for $48 \mathrm{~h}$ with AG014699 at concentrations of 10, 30 and $50 \mu \mathrm{mol} / 1$, the protein levels of Caspase 3, Caspase 8 and Bax were higher, compared with those in the control group (Fig. 4A and B), which was also the case in the cells treated with BSI-201 concentrations of 20, 40 and $60 \mu \mathrm{mol} / 1$ (Fig. 4C and D). The protein levels of $\mathrm{Bcl}-2$ in the two treatment groups were reduced, compared with those in the control groups (Fig. 4).

Effects of AG014699 and BSI-201 on HepG2 cell migration. Following treatment of the HepG2 cells for $48 \mathrm{~h}$ with $10 \mu \mathrm{mol} / \mathrm{l}$ of BSI-201 or $5 \mu \mathrm{mol} / 1 \mathrm{AG01469}$, the results showed that the numbers of cells, which migrated into the lower chamber were lower, compared with those in the control groups, and this difference was significant $(\mathrm{P}<0.01$; Fig. 5). When the HepG2 cells were treated with AG014699 at concentrations of 10,30 and $50 \mu \mathrm{mol} / 1$ (Fig. 6A and B) or with BSI-201 at concentrations of 20, 40 and $60 \mu \mathrm{mol} / 1$ (Fig. 6C and D) for $48 \mathrm{~h}$, the protein levels of PTEN and TIMP3 were higher, compared with those in the control group, whereas the levels of MMP3 were lower, compared with those in the control group.

\section{Discussion}

The present study is the first, to the best of our knowledge, to use the AG014699, BSI-201 AZD-2281 PARP-1 inhibitors in vitro to treat hepatoma cell lines, and to show that the three PARP-1 inhibitors were able to inhibit the proliferation of HepG2 cells. In addition, AG014699 and BSI-201 showed superior sensitivity, and were able to induce apoptosis and inhibit the migration of hepatoma cells, the mechanisms of 

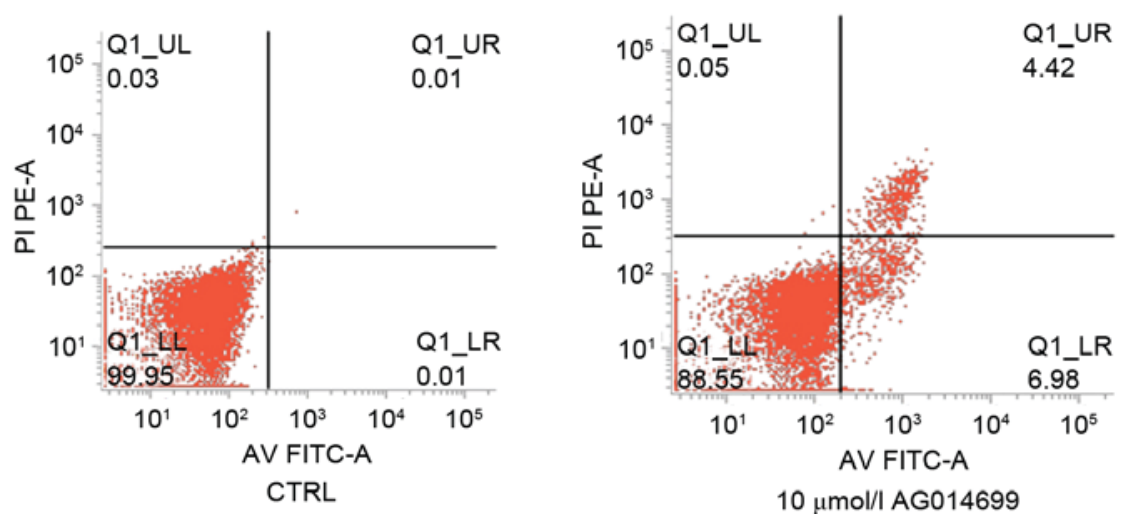

$10 \mu \mathrm{mol} / / \mathrm{AG} 014699$

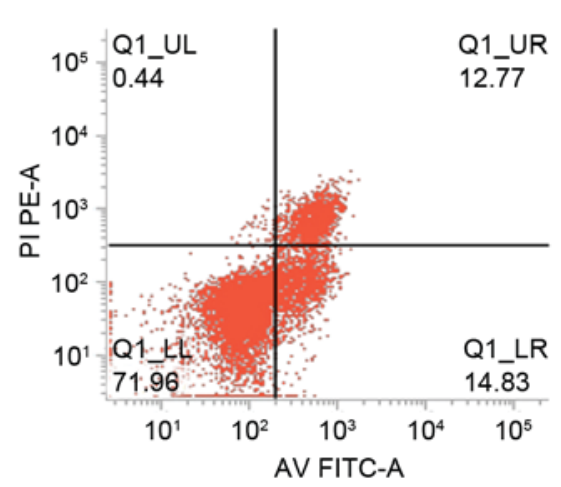

$30 \mu \mathrm{mol} / \mathrm{l}$ AG014699

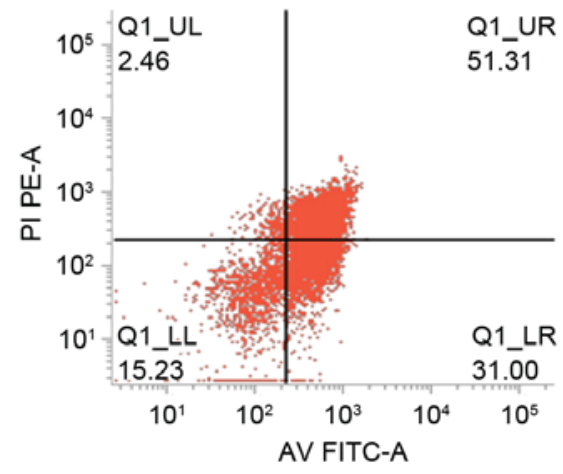

$50 \mu \mathrm{mol} / \mathrm{l} \mathrm{AG014699}$
Figure 2. Apoptotic rates of HepG2 cells treated with different concentrations of AG014699. Apoptotic rates were determined at $48 \mathrm{~h}$. CTRL, control
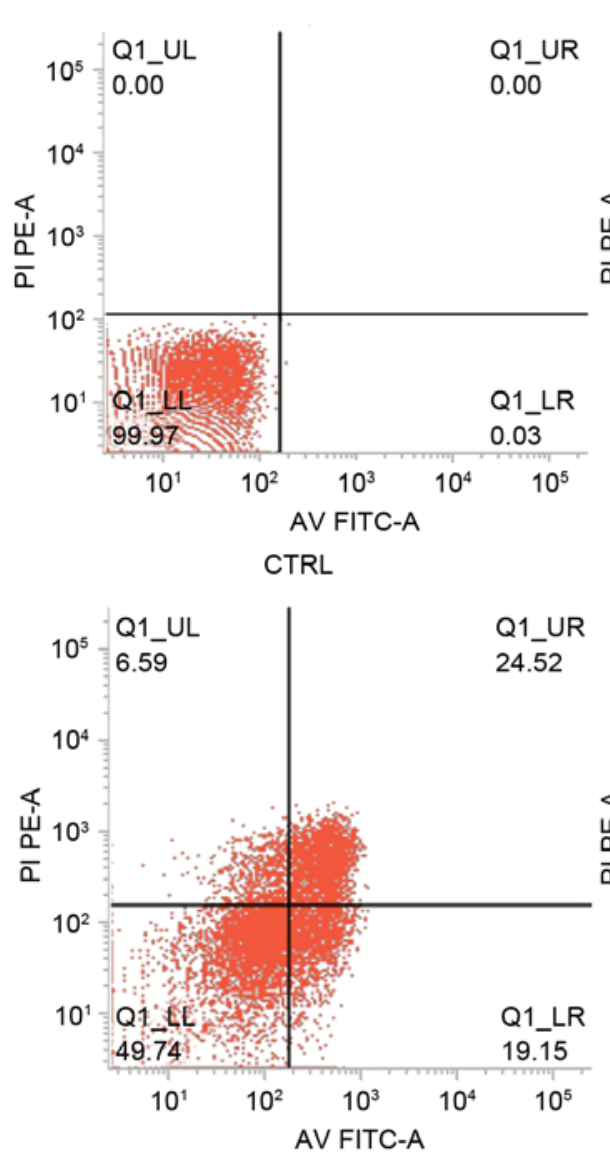

$40 \mu \mathrm{mol} / \mathrm{I} \mathrm{BSI}-201$

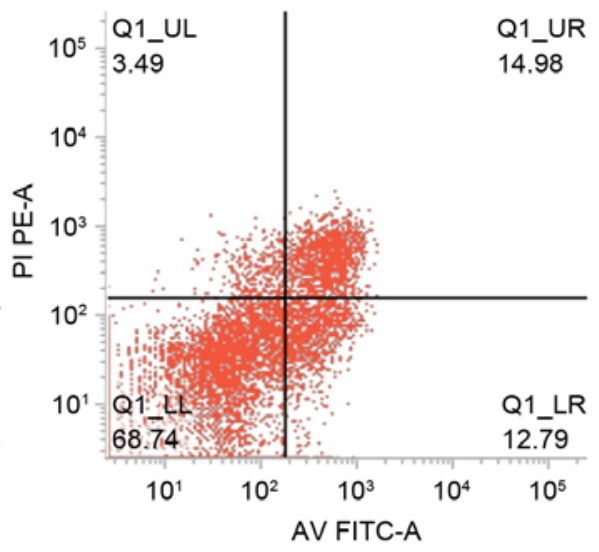

$20 \mu \mathrm{mol} / \mathrm{l} \mathrm{BSI}-201$

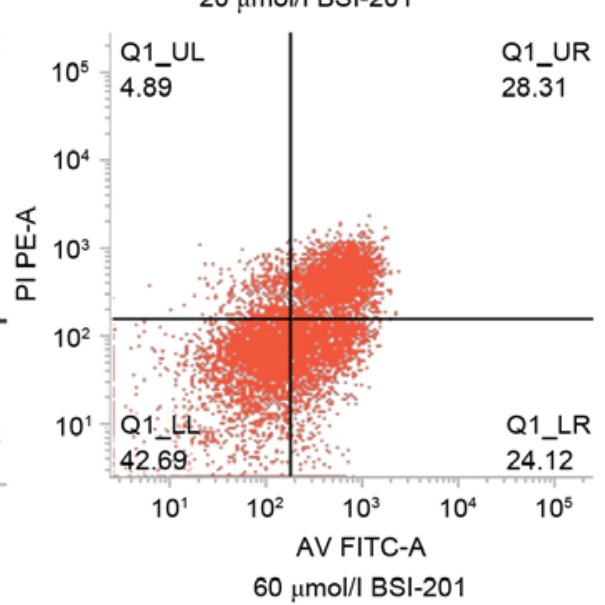

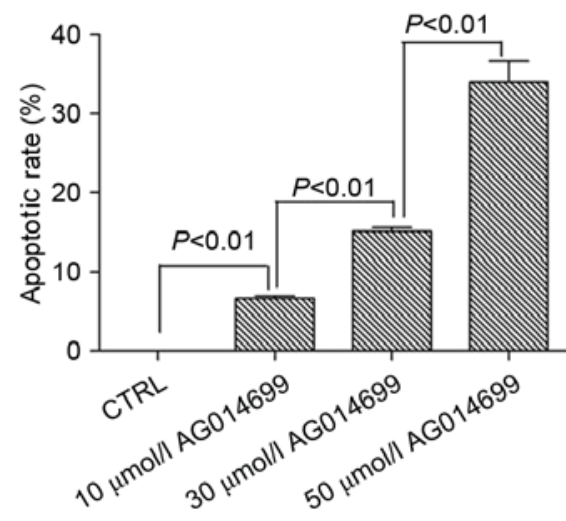

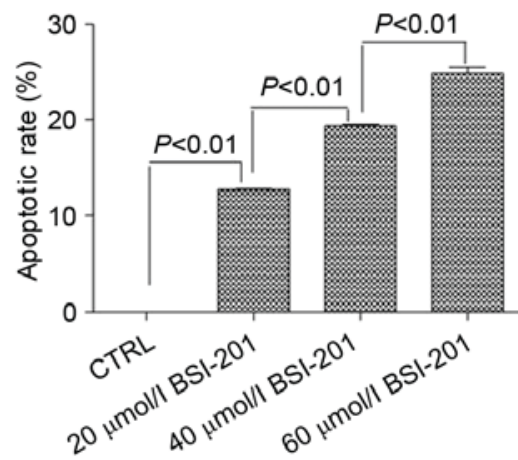

Figure 3. Apoptotic rates of HepG2 cells treated with different concentrations of BSI-201. Apoptotic rates were determined at $48 \mathrm{~h}$. CTRL, control. 

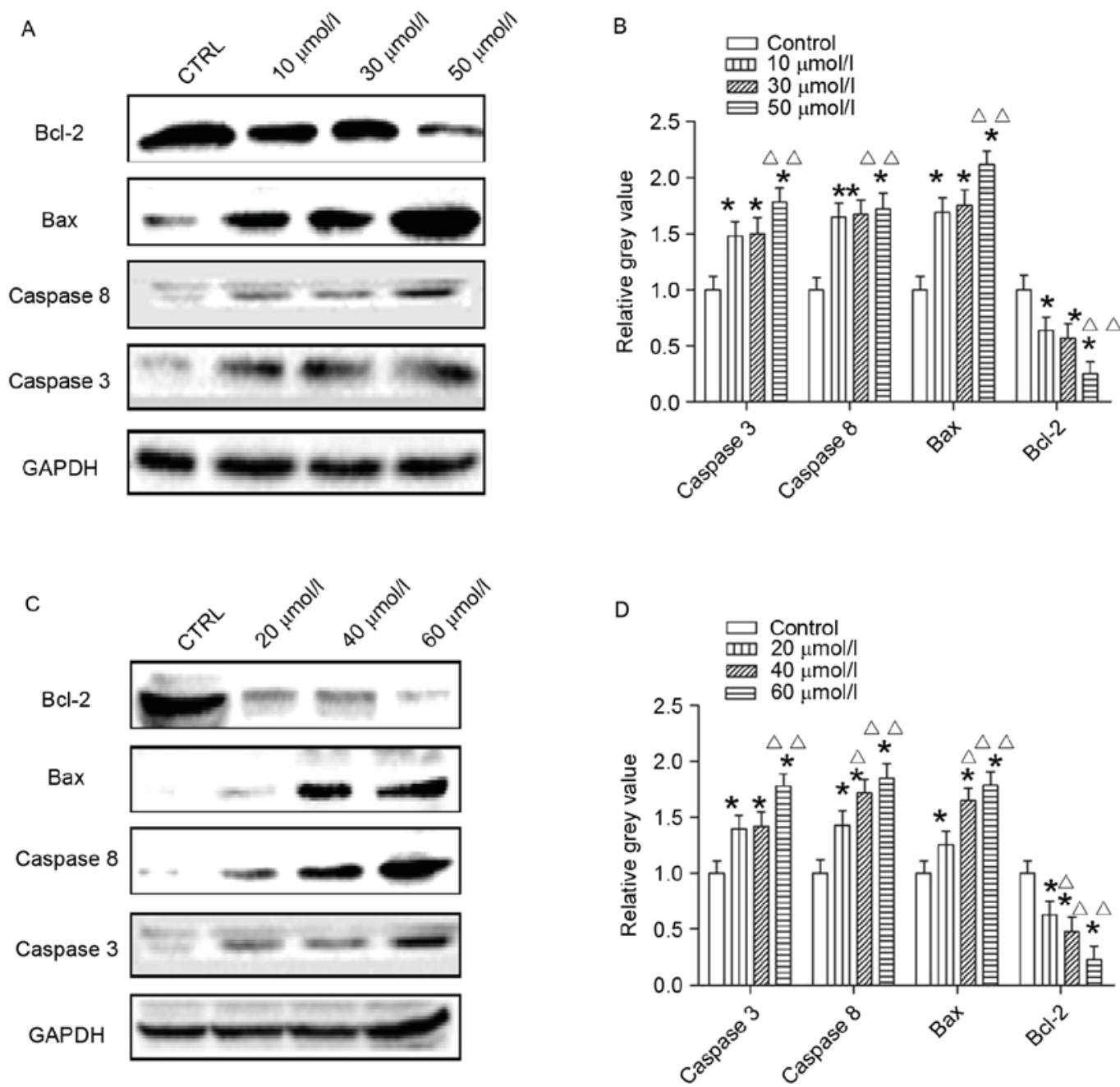

Figure 4. Effects of different concentrations of AG014699 and BSI-201 on protein levels of Caspase 3, Caspase 8, Bax and Bcl-2 in HepG2 cells.(A) Blots showing proteins in cells treated with AGO14699 and (B) quantification. (C) Blots showing proteins in cells treated with (C) BSI-201 and (D) quantification. ${ }^{\prime} \mathrm{P}<0.05$, compared with the control group; ${ }^{\wedge} \mathrm{P}<0.05$, compared with the low dose group; ${ }^{\Delta}{ }^{\Delta} \mathrm{P}<0.05$, compared with the middle dose group. CTRL, control; Bcl-2, B-cell lymphoma 2; BAX, Bcl-2-associated X protein.

which may be associated with altered apoptosis and migration signaling pathways.

Primary liver cancer is a complex pathological process and its detailed mechanism remains to be fully elucidated. DNA damage caused by a variety of factors are important in the process (12). There have been increasing reports on DNA damage repair and tumor occurrence/development, particularly those investigating the association between PARP and the development of tumors (13). PARP-1 may also be involved in the biological function of tumor cells, including tumor cell proliferation, apoptosis, migration and invasion. Previously, Yang et al (14) found that the PARP-1 inhibitor, olaparib, inhibits the cloning of JF-305 pancreatic cancer cells, and inhibits the cell cycle of cells in the $\mathrm{S}$ phase and $\mathrm{G} 2 / \mathrm{M}$ phase of cell formation in vivo. In liver cancer, Munoz-Gamez et al (15) found that the PARP-1 inhibitor, ABT-888, combined with acetazolamide inhibited the proliferation of liver cancer cells and induced cell apoptosis. However, there have been no reports of a sensitive PARP-1 inhibitor of liver cancer cells.
The present study demonstrated that three types of PARP-1 inhibitor, AG014699, BSI-201 and AZD2281, showed inhibitory effects on the proliferation of human hepatoma cells, however, their sensitivities differed. The most sensitive was AG014699, followed by BSI-201 and AZD2281. Chuang et al (16) found that the sensitivities to PARP-1 inhibitors in breast cancer were AG014699>AZD2281>BSI-201, whereas the present study demonstrated that the sensitivities to the PARP-1 inhibitors on HepG2 cells were AG014699>BSI-201>AZD2281. Therefore, different tumor cells may have different sensitivities to different inhibitors. The present study also detected the apoptosis of HepG2 cells treated with AG014699 and BSI-201, which cells were shown to be more sensitive to, and found that AG014699 and BSI-201 induced apoptosis of the HepG2 cells. The highest rates of apoptosis were 31 and $24.82 \%$, respectively. In addition, the protein expression levels of Caspase 3, Caspase 8 and Bax increased, whereas that of Bcl-2 decreased following treatment with the two types of PARP-1 inhibitor. Cell apoptosis includes the mitochondrial pathway, endoplasmic reticulum and death receptor pathway (17). The 


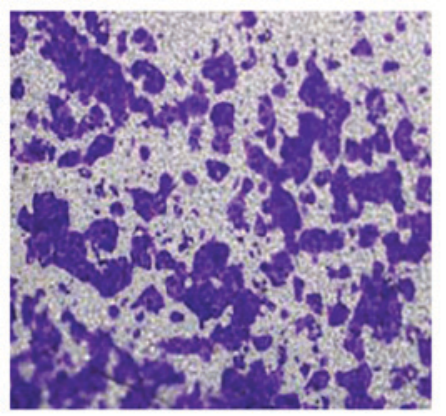

CTRL

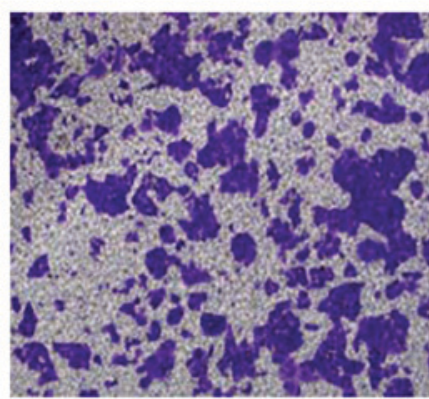

CTRL

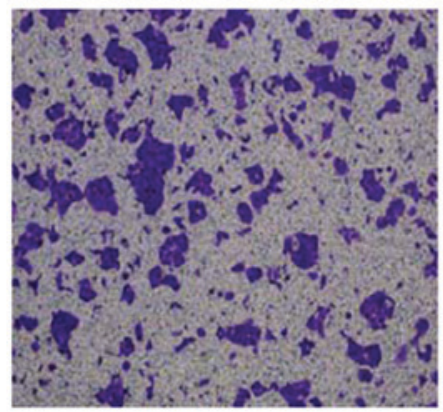

$5 \mu \mathrm{mol} / \mathrm{l} \mathrm{AG014699}$

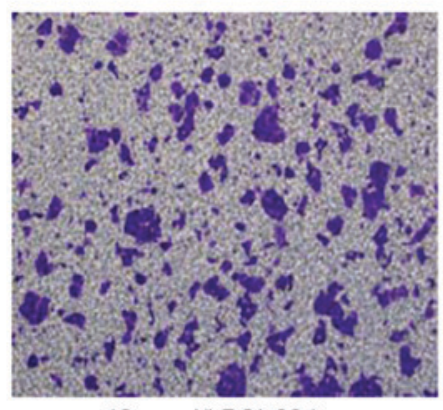

$10 \mu \mathrm{mol} / \mathrm{l} \mathrm{BSI}-201$

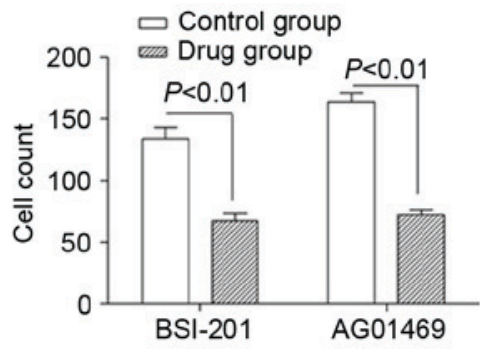

Figure 5. Effects of BSI-201 and AG014699 on the migration of HepG2 cells (magnification, x400). Images on the left show HepG2 cells in 10 mol/1 BSI-201, in $5 \mathrm{~mol} / \mathrm{l} \mathrm{AG014699}$ and in the control groups at $48 \mathrm{~h}$ in the Transwell chamber. The histogram on the right shows the numbers of cells. CTRL, control.
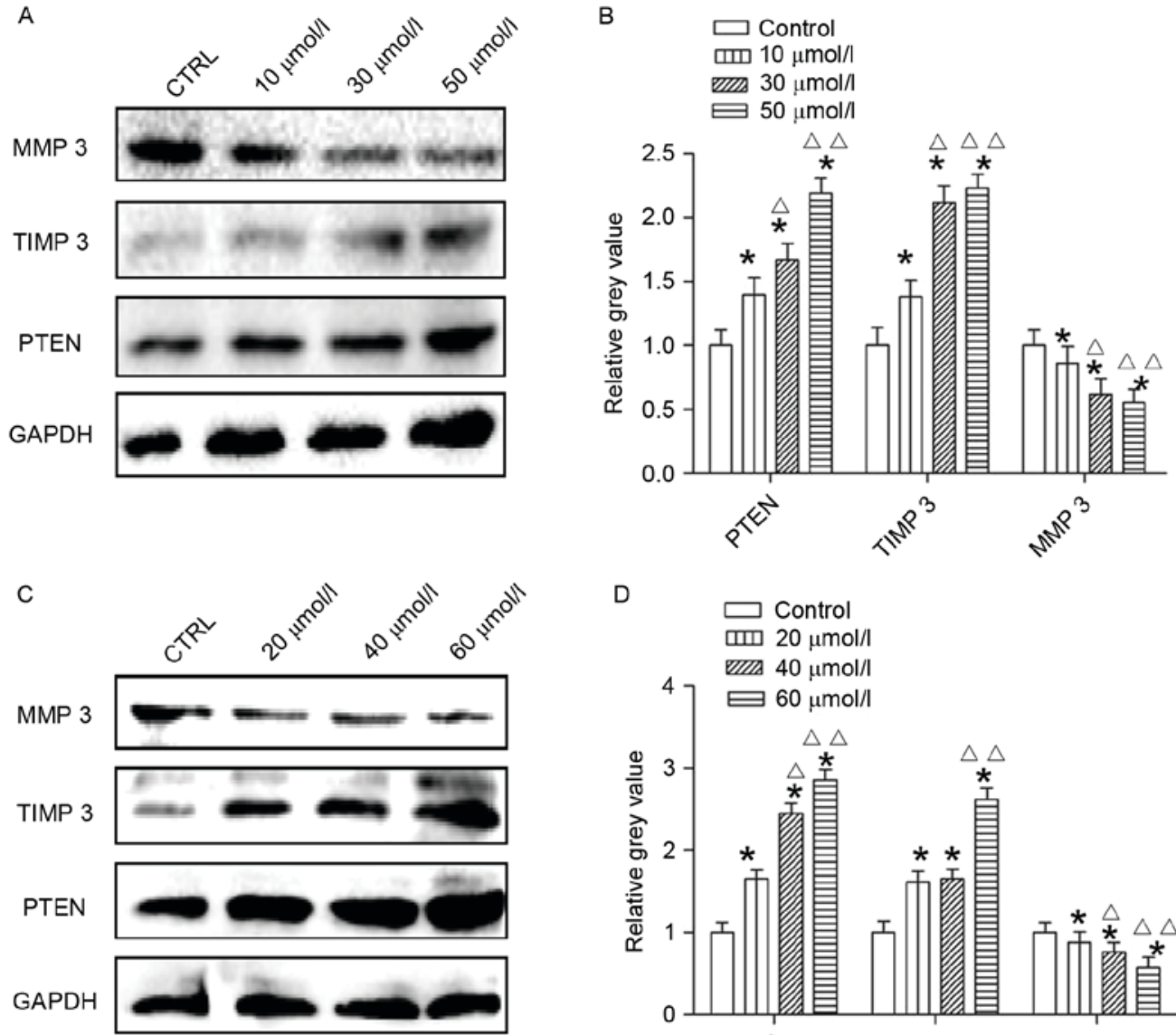

D

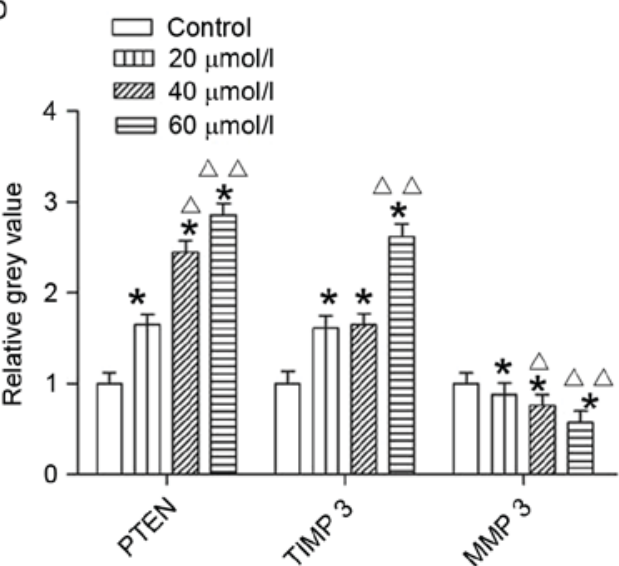

Figure 6. Effects of different concentrations of AG014699 and BSI-201 on protein levels of PTEN, TIMP3 and MMP3 in HepG2 cells. (A) Blots showing protein expression following treatment with AG014699 and (B) quantification. (C) Blots showing protein expression following treatment with BSI-201 and (D) quantification. ${ }^{*} \mathrm{P}<0.05$, compared with the control group; ${ }^{\circ} \mathrm{P}<0.05$, compared with the low dose group, ${ }^{\Delta} \mathrm{P}<0.05$, compared with the middle dose group MMP, matrix metalloproteinase; TIMP 3, tissue inhibitor of metalloproteinase 3; PTEN, phosphatase and tensin homolog; CTRL, control. 
Caspase enzyme system is core to apoptosis, and a variety of apoptotic pathways and apoptotic factors can ultimately activate Caspase enzymes to cause apoptosis (17). The results of the present study showed that Caspase 3, Caspase 8, Bax and Bcl-2 were key molecules in the mitochondrial apoptotic pathway, indicating that PARP-1 inhibitors induced the apoptosis of HepG2 cells through the mitochondrial pathway.

Preventing metastasis in liver cancer is a challenge requiring urgent solutions in the treatment of liver cancer. The present study found that fewer HepG2 cells migrated to the lower Transwell chamber in the inhibitor-treated group, compared with those in the control group. This suggested that AG014699 and BSI-201 inhibited the migration of HepG2 cells. Forster et al (18) found that patients with endometrial cancer, which was sensitive to cisplatin, had prolonged survival rates following treatment with iniparib, and metastases of brain tissue reduced. Biopsy showed that patients were deficient in the PTEN gene, therefore, it was suggested that iniparib may be a novel method for the treatment of tumors with PTEN gene deletion. The present study found that AG014699 and BSI-201 upregulated the expression of PTEN in HepG2 cells, and suggested that AG014699 and BSI-201 may increase the expression of PTEN in HepG2 cells, thereby reducing the migration of the cells.

In the present study, it was found that the AG014699 and BSI-201 inhibitors of PARP-1 regulated the protein expression of TIMP3 in HepG2 cells and downregulated the expression of MMP3. These results suggested that PARP-1 inhibitors upregulated the TIMP-3/MMP-3 ratio to reduce migration of the HepG2 cells.

In conclusion, the present study showed that the three PARP-1 inhibitors inhibited the proliferation of human hepatoma cells in vitro, however, the sensitivity of the three PARP-1 inhibitors were different. AG014699 and BSI-201 may induce the apoptosis of HepG2 cells through the mitochondrial pathway, and reduce the migration of HepG2 cells by upregulating the protein expression of PTEN and increasing the TIMP-3/MMP-3 ratio. However, further investigations are required to elucidate the detailed mechanism for the treatment of liver cancer.

\section{Acknowledgements}

This study was supported by the Technical Research and Development Project of Gansu Province (grant no. 1305TCYA023).

\section{References}

1. Lafaro KJ, Demirjian AN and Pawlik TM: Epidemiology of hepatocellular carcinoma. Surg Oncol Clin N Am 24: 1-17, 2015.
2. Fan Y and Zong WX: PARP Activation and Necrotic Cell Death. In: Necrotic Cell Death. Shen HM, Vandenabeele P (eds) Springer; New York, NY: pp 163-175, 2014.

3. Speers C, Feng FY and Pierce LJ: PARP-1 inhibitors and radiotherapy sensitivity: Future prospects for therapy? Breast Cancer Management 3: 281-296, 2014.

4. Somlo G, Frankel P, Luu T, Ma C, Arun B, Garcia A, Cigler T, Harvey HA, Sparano JA, et al: Phase II trial of single agent PARP inhibitor ABT-888 (veliparib [vel]) followed by postprogression therapy of vel with carboplatin (carb) in patients (pts) with stage BRCA-associated metastatic breast caner (MBC): California Cancer Consortium trial PHII-96. J Clin Oncol 32 (suppl): S1021, 2014.

5. Stewart E, Goshorn R, Bradley C, Griffiths LM, Benavente C, Twarog NR, Miller GM, Caufield W, Freeman BB III, Bahrami A, et al: Targeting the DNA repair pathway in ewing sarcoma. Cell Rep 9: 829-841, 2014.

6. Cipak L and Jantova S: PARP-1 inhibitors: A novel genetically specific agents for cancer therapy. Neoplasma 57: 401-405, 2010.

7. Ibrahim YH, Garcia-Garcia C, Serra V,He L, Torres-Lockhart K, Prat A, Anton P, Cozar P, Guzmán M, Grueso J, et al: PI3K inhibition impairs BRCA1/2 expression and sensitizes BRCA-proficient triple-negative breast cancer to PARP inhibition. Cancer Discov 2: 1036-1047, 2012.

8. Zhou X, Huang ZY, Chen XP and Huang SH: Suppressive effect of poly (ADP-ribose)polymerase-1 inhibitor PJ34 on human hepatoma cell line HepG2. World Chinese Journal of Digestology 15: 1806-1809, 2007. (In Chinese)

9. Milella M, Falcone I, Conciatori F, Cesta Incani U, Del Curatolo A, Inzerilli N, Nuzzo CM, Vaccaro V, Vari S, Cognetti F and Ciuffreda L: PTEN: Multiple functions in human malignant tumors. Front Oncol 5: 24, 2015.

10. Banik D, Netherby CS, Bogner PN and Abrams SI: MMP3-mediated tumor progression is controlled transcriptionally by a novel IRF8-MMP3 interaction. Oncotarget 6: 15164-15179, 2015.

11. Domagala P, Huzarski T, Lubinski J, Gugala K and Domagala W: PARP-1 expression in breast cancer including BRCA1-associated, triple negative and basal-like tumors: Possible implications for PARP-1 inhibitor therapy. Breast Cancer Res Treat 127: 861-869, 2011.

12. de Lope CR, Tremosini S, Forner A, Reig M and Bruix J: Management of HCC. J Hepatol 56 (Suppl 1): S75-S87, 2012.

13. Golia B, Singh HR and Timinszky G: Poly-ADP-ribosylation signaling during DNA damage repair. Front Biosci (Landmark Ed) 20: 440-457, 2015.

14. Yang X, Ndawula C Jr, Zhou H, Gong X and Jin J: JF-305, a pancreatic cancer cell line is highly sensitive to the PARP inhibitor olaparib. Oncol Lett 9: 757-761, 2015.

15. Muñoz-Gámez JA, López Viota J, Barrientos A, Carazo Á, Sanjuán-Nuñez L, Quiles-Perez R, Muñoz-de-Rueda P, Delgado Á, Ruiz-Extremera Á and Salmerón J: Synergistic cytotoxicity of the poly (ADP-ribose) polymerase inhibitor ABT-888 and temozolomide in dual-drug targeted magnetic nanoparticles. Liver Int 35: 1430-1441 2015.

16. Chuang HC, Kapuriya N, Kulp SK, Chen CS and Shapiro CL: Differential anti-proliferative activities of poly(ADP-ribose) polymerase (PARP) inhibitors in triple-negative breast cancer cells. Breast Cancer Res Treat 134: 649-659, 2012.

17. Fiandalo MV and Kyprianou N: Caspase control: Protagonists of cancer cell apoptosis. Exp Oncol 34: 165-175, 2012.

18. Forster MD, Dedes KJ, Sandhu S, Frentzas S, Kristeleit R, Ashworth A, Poole CJ, Weigelt B, Kaye SB and Molife LR: Treatment with olaparib in a patient with PTEN-deficient endometrioid endometrial cancer. Nat Rev Clin Oncol 8: 302-306, 2011. 